
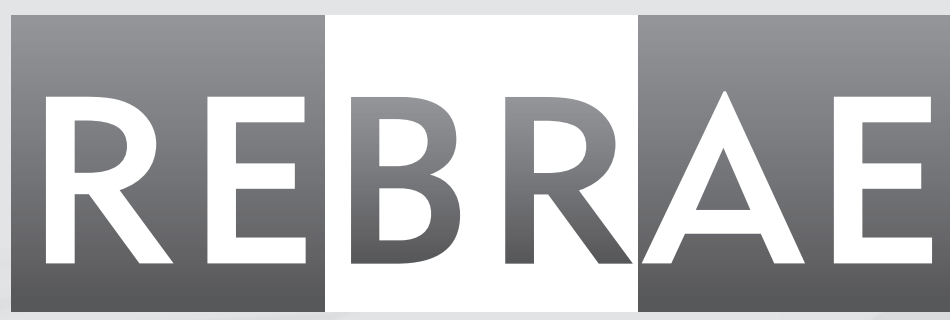

Revista Brasileira de Estratégia 


\title{
Esquemas interpretativos e estratégias institucionais em um sistema de cooperativas de crédito
}

\author{
Interpretive schemes and institutional strategies in a cooperative credit system
}

Antonio Saraiva Junior ${ }^{[a]}$, João Marcelo Crubellate ${ }^{[b]}$

[a] Mestre em Administração pela Universidade Federal do Paraná (UFPR), analista do Banco Central do Brasil, Curitiba, PR - Brasil, e-mail: antonio.saraiva@bcb.gov.br

[b] Doutor em Administração pela Fundação Getúlio Vargas (FGV), professor do Programa de Pós-Graduação em Administração da Universidade Estadual de Maringá (UEM), Maringá, PR - Brasil, e-mail: jmcrubellate@terra.com.br

\section{Resumo}

Neste artigo descrevemos e analisamos mudanças ocorridas nos esquemas interpretativos predominantes na Central Sicredi PR, durante o período de 1995 a 2008, bem como investigamos as relações existentes entre tais mudanças e as estratégias institucionais implementadas ou apoiadas por aquela cooperativa no mesmo período. Partimos da premissa de que o desenvolvimento das cooperativas de crédito tem sido positivamente influenciado por mudanças nas regras institucionais do setor e buscamos investigar o esforço de agência das próprias cooperativas nesse processo de mudança institucional. Trata-se de um estudo de caso único com perspectiva de corte seccional, porém com características longitudinais, considerando o levantamento de dados históricos. As técnicas de tratamento desses dados foram: 1) análise de conteúdo de documentos e entrevistas, e 2) elaboração de mapas cognitivos. 0 principal resultado alcançado foi a caracterização de uma relação de reciprocidade entre as mudanças na visão de mundo dos dirigentes e a implementação das estratégias institucionais, em um processo cujo resultado foi a construção de uma nova identidade para o sistema Sicredi PR.

Palavras-chave: Cooperativismo de crédito. Ambiente institucional. Estratégias institucionais.

\section{Abstract}

In this study we describe and analyse changes occurred at the interpretive schemes prevalent in a Brazilian credit cooperative between 1995 and 2008, and investigate the relations between that changes and the institutional strategies that cooperative implemented at the same period. We took the premise that credit cooperative development has been positively influenced by changes occurred in the field institutional rules and aimed to investigate the credit cooperative agency in this process. It is a qualitative-descriptive study based on concepts developed in the sociological branch of institutional theory. The single case study research strategy was chosen. Content analysis and cognitive maps were the techniques used to process the data. Data were collected and processed in three stages, the first two relating to the collection of documentary data and the third relating to interviews with 
managers involved with institutional strategies implementation. The main result achieved was the description of a reciprocal relationship between changes in the worldview of the leaders and the implementation of institutional strategies, in a process that resulted in the build of a new organizational identity, full of interests and values borrowed from the business logic of the financial market and focused on the development of the system itself.

Keywords: Credit cooperative. Institutional environment. Institutional strategies.

\section{Introdução}

No presente estudo, buscamos descrever e interpretar aspectos cognitivos relacionados ao desenvolvimento de um sistema de crédito cooperativo, tomando por base conceitos e modelos relacionados à teoria institucional. A definição dos elementos que constituíram a pesquisa foi fortemente influenciada pela observação de que as cooperativas de crédito brasileiras possuem história recente, bastante dinâmica e repleta de mudanças, tanto técnicas quanto institucionais. Podemos qualificar o campo organizacional das cooperativas de crédito como um campo jovem e instável e, por isso, rico de mudanças a serem estudadas. 0 segundo fator, que faz do cooperativismo de crédito um campo atraente para pesquisas, é o ritmo de crescimento apresentado pelo setor, o qual se tem destacado positivamente das médias do sistema financeiro como um todo, muito embora ainda possua participação diminuta no mercado total.

As cooperativas de crédito são sociedades integrantes do Sistema Financeiro Nacional (SFN) - e, por essa razão, suas atividades são rigidamente regulamentadas e fiscalizadas pelo governo. Grande parte das mudanças observadas na gestão dessas organizações está relacionada a alterações em leis e normas oficiais. Com frequência, as mudanças nas regras institucionais são resultado da agência de pessoas e organizações interessadas em alterar a ordem institucional vigente para benefício próprio ou de terceiros. Os sistemas de crédito cooperativo, à semelhança de outros setores econômicos, implementam ações com o objetivo de influenciar o ambiente institucional em que estão inseridos, por meio de representantes, formais e informais, incumbidos de defender seus interesses nas diversas esferas políticas e administrativas nas quais as normas que regem seu funcionamento são definidas. Em nível nacional, as principais entidades de representação política das cooperativas são: a Organização das Cooperativas Brasileiras (OCB) - e a Frente Parlamentar do Cooperativismo no Congresso Nacional (FRENCOOP).

Partimos aqui da premissa de que o desenvolvimento das cooperativas de crédito no Brasil foi positivamente influenciado por mudanças nas regras institucionais do setor e expressam a agência das próprias cooperativas sobre essas mudanças. Agência é aqui entendida como processo composto necessariamente de interpretação e ação. A ação não ocorre sem reflexão acerca das práticas institucionalizadas e das alternativas de mudanças ao alcance do agente. Reflexão e ação são construídas sobre uma base de crenças, valores e interesses predominantes, que denominamos esquemas interpretativos. Ao mesmo tempo, os esquemas interpretativos são permanentemente reconstruídos pela prática da ação reflexiva. Trata-se, portanto, de um estudo que traz, na base de sua fundamentação teórica, conceitos desenvolvidos no ramo sociológico da teoria institucional (SCOTT, 1992; DIMAGGIO; POWELL, 1983; LAWRENCE, 1999) e a noção de interação recíproca entre agência e estrutura própria da teoria da estruturação (GIDDENS, 1989).

Procuramos demonstrar empiricamente como as organizações podem não apenas fazer escolhas entre alternativas legítimas dadas pelas regras institucionais vigentes, mas também implementar ações com o objetivo de alterar regras, recriando seu próprio ambiente institucional de maneira a facilitar a realização de seus interesses. A análise foi desenvolvida por meio do estudo das relações existentes entre mudanças ocorridas nos esquemas interpretativos predominantes em uma Cooperativa Central de Crédito e estratégicas institucionais implementadas ou apoiadas por essa organização durante o período de 1995 a 2008. As opiniões expressas por estes autores não refletem, necessariamente, o posicionamento do Banco Central do Brasil, tampouco de qualquer outra organização mencionada. 


\section{Instituições e estruturação}

A contínua reconstrução das práticas sociais implica a permanente possibilidade de mudanças tanto na direção de uma institucionalização mais profunda, quanto da desinstitucionalização de uma determinada prática. 0 processo de institucionalização envolve, ainda, a tipificação recíproca dos atores que executam as atividades, que dá origem aos papéis sociais. A apreensão, pelo indivíduo, do mundo social como uma coisa (entidade?) real depende de que esse indivíduo interiorize e desempenhe os papéis sociais a ele atribuídos. Os papéis são, dessa forma, a representação por excelência das instituições (BERGER; LUCKMANN, 1983).

De forma consonante, Giddens (1989) argumenta que apenas podem ser designadas como instituições as práticas que possuem a maior extensão espaço-temporal dentro de uma totalidade social. Em outras palavras, toda (toda a?) atividade objetivada está inserida em um processo de institucionalização, mas apenas as práticas que logram alcançar alto grau de legitimação em uma sociedade e relativa estabilidade ao longo do tempo devem ser chamadas de instituições. Para Giddens (1989), o conjunto de regras e recursos envolvidos na produção e reprodução de práticas sociais constitui uma ordem virtual de relações transformadoras, que ele denomina estrutura. Tais regras e recursos não se referem às próprias práticas, mas às propriedades que possibilitam a constante reprodução das práticas pelos atores sociais. As propriedades estruturais não limitam apenas, mas igualmente possibilitam a reprodução social. Uma implicação disso é que a estrutura proporciona os meios tanto para a sedimentação das práticas vigentes, quanto para sua mudança.

Outro aspecto do estruturacionismo é a relação entre reprodução social, agência e reflexividade. Segundo Giddens (1989), todo ator social é um potencial agente. A agência não exige intencionalidade, mas apenas a capacidade de fazer a diferença, ou seja, o poder de agência reside na simples possibilidade de agir ou não agir e, dessa forma, influenciar os acontecimentos em curso. Quanto ao resultado dessa ação, pode ou não decorrer da intenção de provocá-lo. Contudo a reprodução das práticas sociais exige, além da capacidade de agência, a reflexividade do ator sobre suas ações, isto é, a capacidade humana de refletir sobre seus próprios atos e sua situação. Para Giddens (1989, p. 2):
A continuidade de práticas presume reflexividade, mas esta, por sua vez, só é possível devido à continuidade de práticas que as tornam nitidamente 'as mesmas' através do espaço e do tempo. Logo, a 'reflexividade' deve ser entendida não meramente como 'autoconsciência', mas como o caráter monitorado do fluxo contínuo da vida social.

Emirbayer e Mische (1998) desenvolvem uma abordagem mais ampla da questão, contemplando não apenas a relação recursiva da agência com as práticas sociais, mas também sua faceta mais voluntarista. Eles argumentam que a ação social é composta por uma combinação de três orientações temporais: a primeira, dirigida ao passado, estimula um comportamento habitual não reflexivo que promove a reprodução das instituições vigentes; a segunda, dirigida ao futuro, corresponde à prospecção de configurações sociais alternativas; e a terceira, dirigida ao presente, possibilita um julgamento pragmático acerca da viabilidade das alternativas existentes, dados os limites do contexto presente. As três orientações estão sempre presentes na vida social, sendo que o comportamento dos atores pode mudar, de uma ênfase na orientação ao passado para uma ênfase na orientação para o futuro, quando eles são expostos a situações problemáticas que requeiram maior grau de reflexividade.

\section{Lógicas institucionais}

Thornton e Ocasio (1999, p. 804) definem lógicas institucionais como "padrões históricos socialmente construídos de práticas materiais, pressupostos, valores, crenças e regras pelas quais os indivíduos produzem e reproduzem sua subsistência material, organizam o tempo e o espaço e proporcionam significado à sua realidade social". Tais lógicas modelam as regras formais e informais de ação, interação e interpretação que guiam e limitam os tomadores de decisões em organizações (THORNTON; OCASIO, 2008). Essas regras constituem conjunto de pressupostos e valores, geralmente implícitos, sobre como interpretar a realidade organizacional e o que constitui um comportamento apropriado. Assim, as lógicas ajudam indivíduos e organizações a lidar com a ambiguidade do ambiente e com suas próprias limitações cognitivas, focando sua atenção em um conjunto limitado de questões e soluções. 
Embora forças econômicas incidam sobre a organização, a maneira como os atores interpretam o significado e as consequências dessas forças econômicas é definida por lógicas institucionais que transcendem o domínio organizacional, alcançando a sociedade como um todo. Mudanças na lógica predominante na organização podem afetar quais condições econômicas são vistas como problemáticas e como elas podem ser tratadas por mudanças na estratégia e na estrutura organizacional (THORNTON, 2002). Assim, podemos dizer também que as lógicas institucionais estabelecem relações de pertencimento e legitimidade dos atores organizacionais com o ambiente.

Os principais setores institucionais da sociedade - a família, a religião, as profissões, o estado, as corporações e o mercado - oferecem um conjunto de lógicas que, em determinadas situações, se complementam e em outras se contradizem (THORNTON, 2002). Na maior parte dos campos, os atores organizacionais convivem com a multiplicidade de lógicas institucionais e seus eventuais conflitos. Contudo em cada campo organizacional uma lógica institucional tende a predominar, assegurando a estabilidade das relações entre seus membros (BATTILANA, 2006). Por esta perspectiva, os interesses individuais, as relações de poder e a política nas organizações são moldados pelas lógicas institucionais predominantes no ambiente, as quais variam ao longo do tempo e são influenciadas pelas mudanças que ocorrem nas estruturas econômicas e sociais (THORNTON; OCASIO, 1999). As lógicas institucionais estão presentes nos diversos setores da sociedade e em todos os níveis de análise, o que proporciona inúmeras oportunidades de interação entre elas, tanto no sentido de uma complementaridade que reforça sua reprodução como no de contradições que levam a mudanças (CLEMENS; COOK, 1999).

Friedland e Alford (1991) argumentam que, além de não haver harmonia entre as várias combinações institucionais existentes, pode não haver consenso dentro de uma sociedade com relação a quais crenças são apropriadas a certas situações, sendo comuns disputas entre grupos, organizações e classes pela definição de qual lógica institucional deve orientar determinada atividade. Uma vez que o sistema de regras contido na lógica institucional predominante define a legitimidade de práticas, interesses e relações de poder no campo, as próprias regras tornam-se um importante tipo de recurso, e aqueles que podem controlá-las ou influenciá-las possuem uma valiosa forma de poder (SCOTT, 1987).

\section{Estratégias institucionais}

As estratégias institucionais a que nos referimos são definidas por Lawrence (1999, p. 161) como "padrões de ação organizacional, destinados à gestão das estruturas institucionais em que firmas competem por recursos, ou à reprodução ou transformação dessas estruturas". 0 autor descreve dois tipos de estratégia institucional:

(i) estratégias de pertencimento, que envolvem a definição de regras de pertencimento e seus significados para uma comunidade institucional; e (ii) estratégias de padronização, que se ocupam do estabelecimento de padrões técnicos, legais ou de mercado que definem os processos normais envolvidos na produção de algum produto ou serviço (LAWRENCE, 1999, p. 161).

As regras de pertencimento organizam as interações, as estruturas de dominação e o compartilhamento de informações entre atores engajados em um empreendimento comum, enquanto os padrões de práticas proporcionam diretrizes, normas e prescrições legais relativas a como as práticas devem ser exercidas dentro de um determinado ambiente institucional. Lawrence (1999) associa primariamente as regras de pertencimento com o isomorfismo normativo, tendo em vista sua relação direta com coletividades, como associações profissionais e industriais e comitês reguladores. Já os padrões de práticas estariam mais diretamente associados aos isomorfismos coercitivo - relacionado à adoção obrigatória de determinadas práticas - e mimético - resultante da procura de respostas para situações ambíguas ou de incerteza. 0 autor afirma também que as estratégias institucionais incluem ações tanto no sentido de estabilizar regras e práticas, promovendo sua institucionalização, quanto no de enfraquecer instituições existentes, criando espaço para a transformação do ambiente. As regras institucionais privilegiam alguns grupos de interesse em detrimento de outros, motivando os atores menos privilegiados pelas regras existentes a trabalharem para superá-las ou transformá-las (BOURDIEU, 1993 apud LAWRENCE, 1999) e, assim, proporcionando os meios e motivos tanto para a persistência quanto para a mudança. 
As estratégias de pertencimento mais comuns envolvem a influência sobre associações profissionais e empresariais, órgãos reguladores e grupos de interesse por meio da disseminação de informações que contribuam para a reflexão sobre a inadequação de regras vigentes e para a legitimação de contextos alternativos. Lawrence (1999) propõe que:

A habilidade de uma organização de afetar as regras de pertencimento de um campo organizacional está positivamente associada com seu controle sobre a informação institucional e com o grau em que tal organização é percebida como uma líder no campo.

As estratégias de padronização frequentemente buscam o desenvolvimento de pressões coercitivas ou miméticas (DIMAGGIO; POWELL, 1983) para levar outros atores a se conformarem aos padrões institucionais, mas também podem envolver a institucionalização de práticas, produtos ou serviços por meio de mecanismos culturais. Essas estratégias operam no nível do campo organizacional e podem visar à institucionalização de práticas já legitimadas dentro da organização ou cujos padrões privilegiem sua posição estratégica diante da concorrência. Lawrence (1999, p. 179-180) propõe que:

A habilidade de uma organização de afetar os padrões de práticas em um campo organizacional está positivamente associada com sua expertise técnica, legal, política e de marketing e com o grau em que a mesma é percebida como uma organização líder no campo.

\section{Esquemas interpretativos}

Por maior que seja o grau de institucionalização de uma prática social, a influência desta sobre as ações dos indivíduos e, por conseguinte, sobre sua própria reprodução, somente pode ocorrer por meio de um processo de interpretação. Conforme Machado-da-Silva, Fonseca e Crubellate (2005, p. 26), "a interpretação é o mecanismo operacional, de natureza cognitivo-cultural, da recursividade inerente à institucionalização. É o que desencadeia a reciprocidade entre estrutura e agência". Assim, as estratégias implementadas por uma organização não decorrem apenas da escolha racional de seus dirigentes, mas decorrem também de uma construção social da qual fazem parte todos os atores que participam dos processos estratégicos e na qual a realidade organizacional é constantemente recriada por um processo recursivo de compartilhamento intersubjetivo de interpretações, em que os atores agem com base em hábitos (passado), julgamentos (presente) e projeções (futuro), como demonstraram Emirbayer e Mische (1998). As ideias, valores e crenças subjacentes a esses elementos que orientam a interpretação formam os esquemas interpretativos, que constituem a visão de mundo e o modo próprio de fazer as coisas, específicos de cada organização. Outros autores apontam também a influência dos interesses, definidos como os objetivos econômicos individuais ou de grupos, compondo ou interagindo com os esquemas interpretativos (RANSON; HININGS; GREENWOOD, 1980; BARTUNEK, 1984).

Neste estudo, definimos os esquemas interpretativos como o conjunto de crenças, valores e interesses que se manifestam de forma predominante na organização, constituindo os pressupostos nos quais se baseiam tanto a interpretação dos elementos que compõem o ambiente quanto a tomada de decisões dentro da organização. Dessa forma, procuramos abarcar todos os aspectos essenciais para o entendimento da relação interpretação-ação. Embora possuam elementos comuns (valores e crenças) com o conceito de lógica institucional, os esquemas interpretativos distinguem-se por pertencerem a uma determinada organização ou a um campo organizacional.

As crenças são os pressupostos mais arraigados e menos conscientes. Elas fornecem aos atores organizacionais as expectativas que influenciam suas percepções, pensamentos e emoções sobre o mundo e a organização (MACHADO-DA-SILVA; FONSECA; FERNANDES, 1999). Os valores podem ser definidos como objetos ou fins considerados pelos dirigentes como sendo moralmente desejáveis, tanto para si, quanto para as demais pessoas (ou demais organizações), enquanto os interesses são objetos ou fins econômica ou materialmente desejados por pessoas ou grupos, uma vez que são entendidos como vantajosos como instrumento para o atendimento de suas necessidades reais ou potenciais.

Sendo os esquemas interpretativos esses arranjos de pressupostos em que se baseiam a estrutura organizacional, as estratégias e todo o relacionamento da organização com o ambiente, toda alteração nos esquemas interpretativos predominantes 
invariavelmente acarretará mudanças nesses elementos da organização. Por outro lado, mudanças ambientais também podem levar os esquemas interpretativos a serem questionados (MACHADO-DASILVA; FONSECA; FERNANDES, 1999). À medida que a organização interage com o ambiente, seja no sentido de modificá-lo, seja simplesmente de conformar-se a suas exigências, os esquemas interpretativos dos seus membros vão sendo reconstruídos. A atualização dos esquemas interpretativos é uma necessidade da organização, pois a falta dela pode torná-la incapaz de reagir adequadamente às mudanças do ambiente e manter sua eficiência (BARR; STIMPERT; HUFF, 1992; MACHADO-DA-SILVA; FONSECA; FERNANDES, 1999). Assim, um dos pressupostos deste estudo é o de que uma organização bem-sucedida ao longo do tempo apresenta capacidade de atualizar seus esquemas interpretativos, mantendo-se apta a participar ativamente da reprodução e mudança de seu ambiente.

\section{Aspectos metodológicos}

A pesquisa, de natureza qualitativo-descritiva, consistiu em um estudo de caso único na Cooperativa Central de Crédito do Paraná - Central Sicredi PR com uma perspectiva de corte seccional, mas com características longitudinais, considerando o levantamento de dados históricos, relativos ao período compreendido entre 1995 e 2008.

As técnicas de tratamento dos dados foram a análise de conteúdo e a elaboração de mapas cognitivos. A análise de conteúdo foi qualitativa, e a unidade de significação foi o tema, que, para Bardin (2004), é geralmente utilizado como unidade de registro para estudar motivações de opiniões, de atitudes, de valores, de crenças, de tendências, etc. A análise, baseada no agrupamento, interpretação e triangulação dos registros escritos, buscou revelar os principais elementos constituintes da visão que os gestores da cooperativa tinham da própria organização, de suas perspectivas de desenvolvimento e do ambiente no qual ela encontrava-se inserida. A coleta e o tratamento dos dados foram realizados em três etapas, sendo as duas primeiras relativas à coleta de dados documentais e a terceira referente a entrevistas, gravadas e transcritas, com gestores escolhidos pelo seu envolvimento com as estratégias institucionais identificadas, das quais a Central Sicredi PR participou diretamente ou por meio de órgãos de representação, como a OCB e a Organização das Cooperativas do Estado do Paraná (Ocepar).

Os elementos constitutivos dos esquemas interpretativos (crenças, valores e interesses) foram identificados por meio da análise e triangulação de dados provenientes de atas de reuniões realizadas ao longo do período de análise (1995 a 2008), de outras fontes documentais e das entrevistas com gestores selecionados. Foram analisadas 262 atas de reuniões, além de outros documentos, dos quais conseguimos obter 1.291 registros válidos para este estudo (notações vinculadas às categorias de análise). Além disso, foram realizadas oito entrevistas com dirigentes atuais e ex-dirigentes da organização, com duração média de 90 minutos cada uma. Todos esses dados permitiram a elaboração de três mapas cognitivos, correspondentes às principais mudanças identificadas no estudo.

Foram consideradas válidas para a análise manifestações dos dirigentes que expressavam convicções compartilhadas acerca da organização e do ambiente institucional em que a mesma estava inserida, dos objetivos que deveriam ser perseguidos pelo sistema cooperativo e dos meios e fins econômicos adequados ao desenvolvimento da organização. As mudanças ocorridas foram registradas nos mapas cognitivos. A caracterização do ambiente institucional se restringiu à identificação de princípios universais do cooperativismo e categorias de normas oficiais que incidem sobre as cooperativas de crédito.

\section{O caso em estudo}

O Sistema Nacional de Crédito Cooperativo (SNCC) -, regulamentado pela Lei Complementar n. 130, de 17 de abril de 2009, é oficialmente composto por quatro tipos de entidades: cooperativas singulares de crédito, cooperativas centrais de crédito, confederações de cooperativas de crédito e bancos cooperativos. As singulares funcionam de maneira semelhante aos bancos, oferecendo essencialmente os mesmos produtos e serviços: conta corrente, talão de cheques, cartões de crédito e débito, investimentos, empréstimos, transações eletrônicas, etc. Contudo, somente podem realizar essas operações com as pessoas a elas associadas. Às cooperativas centrais, que podem ter abrangência interestadual, cabe organizar serviços financeiros 
e técnicos de interesse das cooperativas singulares filiadas, além de integrar e orientar as atividades dessas entidades. As confederações de cooperativas de crédito devem coordenar e executar atividades das associadas quando a abrangência dos serviços ultrapassar a capacidade das cooperativas centrais de crédito. Os bancos cooperativos têm o objetivo de proporcionar acesso pleno das cooperativas de crédito ao mercado financeiro (ANCC, 2010; PORTAL DO COOPERATIVISMO DE CRÉDITO, 2010).

O surgimento das primeiras cooperativas de crédito no Paraná, em 1981, e a criação da Cocecrer PR (atual Central Sicredi PR), em 1985, foram eventos diretamente ligados ao movimento de reorganização do cooperativismo de crédito surgido no Rio Grande do Sul, cujo marco inicial foi a criação da Cocecrer RS, em 27 de outubro de 1980. Contudo os dois sistemas desenvolveram-se apartados, ainda que mantendo constante troca de informações, até 1996, quando a central gaúcha, tendo logrado êxito em constituir o primeiro banco cooperativo no país (Banco Cooperativo Sicredi S.A. - Bansicredi), convidou a central paranaense para, juntas, formarem o Sistema Sicredi Interestadual. Em 31 de março de 2000, foi constituída a Confederação Interestadual das Cooperativas Ligadas ao Sicredi - Confederação Sicredi, com o objetivo de prestar serviços ao sistema e entidades conveniadas e, em 2009, foi criada a holding Sicredi Participações S.A. (Sicredipar), com a missão de coordenar as decisões estratégicas do sistema e que passou a controlar o Bansicredi, a Confederação Sicredi e a Fundação Sicredi (PORTAL DO COOPERATIVISMO DE CRÉDITO, 2010).

\section{A central antes da integração}

No início de suas atividades, as primeiras cooperativas de crédito paranaenses funcionavam como departamentos de crédito dentro de cooperativas agropecuárias. Em geral, todos os recursos materiais e humanos necessários eram cedidos pelas cooperativas de produção, o que permitiu que as cooperativas de crédito se mantivessem superavitárias apesar de todas as restrições a que estavam sujeitas, pois seu custo operacional era muito baixo. Outros fatores, que também favoreceram o desenvolvimento dessas novas cooperativas de crédito, foram o apoio do Banco Nacional de Crédito Cooperativo (BNCC), que disponibilizava sua conta de compensação para uso das cooperativas sem qualquer ônus, e as receitas obtidas com a aplicação dos recursos dos depósitos à vista dos associados, tendo em vista as altas taxas de inflação da época. Contudo, em 1990 o governo extinguiu o BNCC, o que obrigou a Cocecrer PR a celebrar convênio com o Banco do Brasil para a compensação de cheques e outros papéis de suas filiadas.

As circunstâncias que deram origem às cooperativas de crédito paranaenses e à própria Cocecrer PR justificam, em grande parte, a visão de mundo predominante naquele sistema até 1995 . Mesmo depois que as cooperativas de crédito fundaram a Central paranaense, passando a constituir um sistema de crédito cooperativo autônomo, a gestão daquelas continuou fortemente vinculada aos interesses das cooperativas de produção, e sua missão restrita ao atendimento das necessidades dos produtores rurais associados.

Em 1995, início do período analisado, o cooperativismo de crédito enfrentava uma série de restrições normativas que limitavam suas atividades. Mesmo assim, os dirigentes da Cocecrer PR depositavam confiança no desenvolvimento do sistema, pois entendiam que o crédito cooperativo era o mais eficiente instrumento para financiar a produção rural. Tal crença vinha sendo construída ao longo dos últimos anos, nos quais as cooperativas de crédito vinham apresentando um progresso considerável decorrente, por um lado, da expansão da produção agrícola e, por outro, da falta de disposição dos bancos em assumirem o risco de conceder créditos diretamente aos produtores rurais.

Havia uma visão crítica a respeito das normas que regiam o funcionamento do cooperativismo de crédito no país, alimentada pelas mudanças na conjuntura econômica ocorridas em 1994 (Plano Real), que levou os gestores cooperativistas a se concentrarem na necessidade de romper barreiras e elevarem o sistema a outro nível de independência e eficiência econômica. As preocupações mais expressadas pelos gestores diziam respeito aos efeitos diretos da estabilização econômica na intermediação financeira (diminuição das receitas com o floating bancário e perspectiva de queda da taxa de juros), à descapitalização das cooperativas de produção e seus reflexos no relacionamento com as cooperativas de crédito, ao aumento generalizado da inadimplência nas operações de crédito e ao alto custo do convênio de compensação de cheques mantido com o Banco do Brasil.

Como resposta a essas preocupações, algumas ideias que já vinham sendo desenvolvidas na 
Cocecrer PR ganharam maior atenção, entre elas a independência administrativa das cooperativas filiadas em relação a suas cooperativas de produção 'irmãs', a expansão da captação de recursos junto a outros segmentos econômicos para reduzir a dependência com o setor rural e, principalmente, a constituição de um banco cooperativo estadual. Os dirigentes estavam convencidos de que apenas um banco próprio poderia assegurar acesso mais econômico e estável ao sistema de compensação de cheques e outros papéis, rentabilidade maior na aplicação das disponibilidades das cooperativas, e parceria para o desenvolvimento de produtos e serviços de natureza bancária, voltados ao atendimento das necessidades dos associados.

No entanto, havia uma impossibilidade legal. Os bancos são sociedades anônimas de capital que obrigatoriamente possuem um acionista controlador. No cooperativismo de crédito isso é impossível por causa da igualdade de voto entre os associados. Essa característica também criava outro problema potencial, derivado da vedação existente a que acionistas controladores operem com a instituição de crédito controlada.

Os ex-dirigentes da Cocecrer PR entrevistados demonstraram grande preocupação em ressaltar a ideia de que o sistema desejava "ter um banco e não ser um banco". Percebe-se que, ao mesmo tempo em que havia o interesse de possuir um banco próprio e, desta forma, não mais depender de instituições com fins lucrativos para ter acesso a serviços essenciais para o sistema, como a compensação de cheques e o acesso a transações interbancárias, havia também receio de que o banco levasse o sistema a perder sua identidade cooperativa. Aparentemente, era intuitiva a ideia de que o banco cooperativo poderia levar o sistema a privilegiar outros valores e interesses que não os que tradicionalmente dirigiram as cooperativas, e isso preocupava os dirigentes da época.

\section{Formação do sistema integrado}

No fim de 1995, a Central Sicredi RS foi autorizada pelo Banco Central a constituir o Bansicredi e ofereceu à Cocecrer PR a oportunidade de associar-se ao banco e constituir um sistema interestadual sob a bandeira Sicredi. Os dirigentes das cooperativas paranaenses reconheceram que seu sistema não tinha, naquele momento, patrimônio e volume de operações suficientes para impulsionar o desenvolvimento de um banco estadual, e concluíram que seria mais vantajosa a associação com aquele sistema.

A autorização para constituição de bancos, pelas cooperativas de crédito, foi fruto de um processo de convencimento das autoridades, por meio da demonstração de que os objetivos eram legítimos e de que as Centrais possuíam as competências necessárias para operar dentro das regras de segurança do sistema financeiro. 0 próprio crescimento do setor foi a melhor demonstração da competência dos sistemas de crédito cooperativo. Mesmo antes de possuir meios próprios de acesso a todas as transações do sistema financeiro, as cooperativas de crédito aumentavam rapidamente seus volumes de ativos e patrimônio. Além disso, sua participação na operacionalização do crédito rural tornava-se cada vez mais representativa. Também as cooperativas agropecuárias, que, com uma produtividade crescente, começavam a ganhar destaque no comércio internacional de alimentos, exerceram pressão sobre os órgãos governamentais em prol do desenvolvimento dos sistemas de crédito cooperativo, já que, através destes, boa parte de seus próprios cooperados conseguia o crédito rural necessário a suas atividades.

Com a integração do Sistema Sicredi, o Bansicredi passou a disseminar novos valores e interesses, que foram se agregando aos esquemas interpretativos da Central paranaense. As mudanças não foram imediatas, tendo em vista que as decisões em um sistema cooperativo têm de ser submetidas às bases, num processo que demanda mais tempo e mais negociações do que normalmente ocorre em uma organização controlada pelo capital. Contudo logo nos primeiros processos de planejamento estratégico após a integração, ficou evidente a mudança de foco a que a Central Sicredi PR seria submetida.

As primeiras mudanças evidenciadas envolveram a verticalização da estrutura do Sistema Sicredi, a segregação de funções estratégicas entre as entidades de terceiro grau e as centrais e o consequente afastamento das cooperativas singulares do processo decisório. Em 1999, o sistema já contava com a participação de quatro cooperativas centrais e as atividades financeiras (gestão da conta centralizada, compensação de cheques e outros papéis, captação de linhas de crédito, gestão de produtos e serviços bancários, etc.) estavam centralizadas no banco cooperativo. Todavia, diversas atividades não financeiras passíveis de serem centralizadas não vinham 
sendo desempenhadas de maneira plenamente satisfatória. Por essa razão, e também para adequar-se às determinações da Resolução CMN n. 2.608/99, acerca das atribuições das cooperativas centrais, foi definida uma reestruturação, que incluiu a criação da Sicredi Serviços - posteriormente definida como a Confederação do Sistema Sicredi - para nela centralizar os serviços não financeiros de interesse geral.

Entre os princípios que nortearam a elaboração do plano de reestruturação, o primeiro foi a previsão de uma atuação diversificada do sistema em todos os setores da economia, com ênfase no fortalecimento da presença do Sicredi nas áreas urbanas. A argumentação apresentada para justificar tal decisão estratégia apontava basicamente uma ameaça e uma oportunidade. A ameaça consistia no risco de perdas elevadas em caso de crise no setor agrícola, tendo em vista a concentração de operações do Sicredi com esse segmento. E a oportunidade era de aproveitar a capacidade ociosa da estrutura do sistema para atender outros segmentos ainda não explorados.

As atribuições definidas para cada entidade evidenciaram o papel de comando do Bansicredi nas decisões comerciais. Embora não houvesse referências explícitas sobre a quem caberia estabelecer o posicionamento estratégico do sistema, ficava clara a separação entre quem definiria "o que" fazer (Bansicredi) e quem se ocuparia de "como" atingir os objetivos (Sicredi Serviços). Para as cooperativas centrais foram reservadas funções essencialmente administrativas e de supervisão do funcionamento das cooperativas singulares. A missão definida para as centrais de "viabilizar a excelência funcional das cooperativas filiadas" traduziu o propósito de fazer cumprir as normas internas e oficiais e os objetivos traçados pela alta administração, dado que a autonomia das cooperativas singulares foi drasticamente reduzida, mantidas, todavia, as características estatutárias essenciais (funcionamento dos órgãos estatutários, assembleias, etc.).

Para coordenar a gestão democrática do sistema, garantindo a representação da base de associados nas decisões de maior relevância, foi criado um Conselho Deliberativo, composto pelos presidentes das cooperativas centrais estaduais, ao qual seriam submetidos os projetos e proposições oriundos das entidades de $3^{\circ}$ grau, passando estas a ser percebidas como as mais competentes para traçar os objetivos e as estratégias operacionais do sistema. Assim, ainda que todas as grandes decisões fossem submetidas à aprovação das bases, a visão de futuro e o projeto de desenvolvimento do sistema passaram a ser estabelecidos com base nas propostas dos gestores do Bansicredi e da Confederação Sicredi. As cooperativas singulares perderam autonomia e influência na condução de seu próprio desenvolvimento. Em contrapartida, ganharam em eficiência operacional e planejamento estratégico. Podemos dizer que, se no cooperativismo originalmente preconizado pela Cocecrer PR, ela trabalhava para harmonizar e defender os interesses de suas filiadas, no cooperativismo 'corporativo' do Sistema Sicredi, a cúpula administrativa busca a maximização da eficiência econômica e a expansão constante do sistema, de maneira a poder oferecer aos associados produtos e serviços bancários em condições competitivas em relação ao mercado financeiro cooperativo e não cooperativo.

Outra mudança radical observada diz respeito à visão dos dirigentes sobre o posicionamento estratégico das cooperativas de crédito paranaenses no mercado. Com a integração, a Central Sicredi PR foi inserida em um arrojado projeto de desenvolvimento em que os conceitos de "eficiência", "crescimento" e "rentabilidade" passam a ocupar o lugar mais alto entre os valores que norteiam as práticas operacionais das cooperativas. Nesta nova visão predominante, o sucesso do Sistema Sicredi depende, sobretudo, de uma rápida expansão, tanto em termos de ativos, quanto de área de atuação, de forma a obter economias de escala e uma participação crescente no mercado financeiro nacional.

\section{Derrubando barreiras}

Fortalecido pela conquista do direito ao banco cooperativo, o Sicredi manteve-se empenhado em alterar outras normas que limitavam seu progresso, sobretudo relacionadas à (i) inclusão das cooperativas de crédito nos programas de crédito rural com equalização de taxas pelo Tesouro Nacional; (ii) isenção da cobrança de PIS/COFINS sobre o resultado do ato cooperativo; (iii) liberação das atividades das cooperativas de crédito nos grandes centros urbanos; e (iv) autorização para constituição de cooperativas de livre admissão.

A partir de 1999, as normas que regem o funcionamento das cooperativas de crédito foram alteradas diversas vezes pelo Conselho Monetário Nacional 
- CMN - (Resoluções CMN nos 2.608/99, 2.771/00, 3.058/02, 3.106/03, 3.140/03, 3.321/05, 3.442/07 e $3.859 / 10)$. De forma geral, todas as alterações foram feitas no sentido de reduzir as restrições de área de atuação e de público associável às cooperativas. Por outro lado, as exigências relativas à supervisão e aos sistemas de controles internos aumentaram, buscando estabelecer um padrão de governança condizente com a maior liberdade de ação que estava sendo proporcionada àquelas sociedades. A Resolução CMN n. 2.608/99 foi a primeira a proporcionar o amparo normativo que faltava às atividades de supervisão da Central sobre suas filiadas, e também abriu caminho para a regulamentação de fundos garantidores de solidez, nos moldes de um programa que já havia sido instituído pela Central Sicredi PR.

A edição da Resolução CMN n. 3.106/2003 lançou a Central Sicredi PR em uma verdadeira corrida de transformações de cooperativas rurais em cooperativas de livre admissão. Considerando o ímpeto de crescimento que o Sicredi demonstrava, a maior razão para a celeridade com que a questão foi tratada pela Central foi o receio de perder para a concorrência o mercado que potencialmente se abria às cooperativas de crédito. Em 2004, o CMN também autorizou os bancos cooperativos a receber depósitos de poupança rural por meio das cooperativas de crédito rural e de livre admissão, proporcionando um acréscimo significativo nos recursos disponíveis para crédito rural (Resolução CMN n. 3.188/04).

Durante todo o período pesquisado, a participação de representantes do Sicredi nos estudos e debates realizados para elaboração ou alteração de normas do CMN foi intensa, como exemplificam os seguintes registros extraídos de atas de reuniões dos dirigentes:

Poupança rural (acesso) - 0 dirigente recuperou o histórico de ações para viabilizar tal intento, lamentando, apenas, o fato de o CECO não ter sido acionado antes sobre a matéria, pois várias teriam sido as oportunidades perdidas para tratar do assunto com autoridades governamentais. Mencionou que essa alternativa de captação de recursos mostra-se ainda mais relevante neste momento em que há dificuldades em relação ao mecanismo da equalização de recursos pelo Tesouro (Ata de 15/12/2003). Relato sobre ações de revisão normativa: o diretor-presidente da Confederação, com auxílio do diretor de políticas corporativas, fez exposição sobre as gestões que estão sendo promovidas no âmbito do
Bacen/CMN. Disse que nutre grandes expectativas sobre avanços substanciais também neste exercício (mantendo a rotina dos últimos anos), citando alguns temas (Ata de 18/02/2005).

No âmbito fiscal, também houve uma importante alteração, que definiu a exclusão das receitas decorrentes do ato cooperativo da base de cálculo do PIS e da Cofins. Mas o acontecimento de maior destaque no ambiente institucional das cooperativas de crédito, após a constituição dos bancos cooperativos, foi a promulgação da Lei Complementar n. 130, que regulamentou o Sistema Nacional de Crédito Cooperativo, previsto no artigo 192 da Constituição Federal de 1988. Embora a nova lei não tenha impactado as práticas operacionais das cooperativas de crédito, posto que suas atividades continuaram a ser regidas pela Lei n. 5.764/71 e pelas normas específicas do SFN, ela proporcionou estabilidade jurídica ao modelo de cooperativismo de crédito instalado no país.

De acordo com os dirigentes entrevistados, o Conselho Especializado do Ramo Crédito da OCB CECO - foi o principal canal de comunicação por onde os sistemas de crédito cooperativo encaminharam seus pleitos e defenderam seus interesses perante os poderes públicos. O CECO é formado pelas cooperativas centrais dos sistemas Sicredi, Sicoob, Unicred e Confebrás, dirigido por representantes desses quatro sistemas. Esses representantes são os responsáveis por discutir suas necessidades com as autoridades (Banco Central, Receita Federal, Ministério da Agricultura, etc.). Normalmente, o CECO atua em duas frentes: a técnica e a política. Um dos exemplos de sua atuação foi o trabalho realizado para a edição da Medida Provisória que excluiu as receitas do ato cooperativo da base de cálculo do PIS/Cofins e sua conversão em lei, episódio em que o CECO coordenou ações de convencimento na Receita Federal, na Casa Civil e no Congresso Nacional. Também foi lembrada a participação da Frente Parlamentar do Cooperativismo de Crédito, com a qual o CECO promove um encontro anual e solicita apoio, sempre que necessário, para a defesa dos interesses das cooperativas de crédito no Congresso Nacional.

\section{Uma nova identidade organizacional}

A partir da integração do Sistema Sicredi, verifica-se um processo de consolidação e amadurecimento 
de uma nova identidade da Central Sicredi PR. Como 'identidade', referimo-nos ao propósito da organização, à sua razão de ser, da maneira como seus próprios dirigentes a percebem (MACHADODA-SILVA; NOGUEIRA, 2001). A integração e a sujeição dos sistemas estaduais à centralização do poder de gestão nas entidades de $3^{\circ}$ grau (banco e confederação) e no Conselho Deliberativo fizeram com que, aos poucos, deixasse de existir uma visão de mundo particular de qualquer uma das centrais. As diferenças e o regionalismo cederam lugar ao processo de homogeneização de crenças, valores e interesses. Constatamos também que, no período subsequente ao processo de integração, há um gradativo recrudescimento de características da nova identidade organizacional; esse processo chegou ao seu ápice com a segunda reestruturação do sistema, iniciada em 2006 e que incluiu a criação da holding Sicredi Participações S/A.

$\mathrm{O}$ primeiro aspecto que se destacou na caracterização da nova identidade da Central Sicredi PR foi a definição de eficiência. Com a associação da Central paranaense ao Bansicredi, a noção de eficiência baseada na satisfação das necessidades do associado foi rapidamente substituída pelo conceito de eficiência estreitamente ligado ao resultado financeiro das operações e à consequente rentabilidade do capital aplicado. Os reflexos dessa mudança nas práticas diárias das entidades não foram imediatos, mas os termos 'eficiência' e 'rentabilidade' logo se tornaram aspectos focais do planejamento estratégico, do estabelecimento e acompanhamento de metas, da capacitação dos recursos humanos e da reestruturação do sistema. Questionado sobre a noção de eficiência predominante na Central antes e depois de sua integração ao Sistema Sicredi, um dos entrevistados explicou que:

Na época em que a Central foi criada, uma cooperativa eficiente era aquela que conseguia atender bem ao produtor, arrumar o repasse de crédito rural, oferecer uma tarifa menor. Porque a cooperativa atendia bem ao seu público, satisfazia aos seus anseios, e conseguia o crédito rural. Hoje isso mudou muito. Hoje a cooperativa eficiente é aquela que se enquadra em todos os itens de exigência da Central. E não são apenas os itens de enquadramento de patrimônio líquido, de liquidez mínima, não é só isso. Ela tem que apresentar rentabilidade, ganho de mercado, índice de penetração dos produtos, ticket médio, etc. E por quê? Porque senão a cooperativa não é rentável, e se ela não for rentável vai causar prejuízo para a sociedade.

A análise da performance das cooperativas filiadas passou a ser item presente na pauta de todas as reuniões do Conselho de Administração da Central, e várias ações foram implementadas com vistas a estimular o desenvolvimento daquelas que apresentavam desempenho insatisfatório. Diversas cooperativas que não obtiveram o desenvolvimento esperado ou apresentaram outros problemas de gestão foram direcionadas pela Central a processos de incorporação ou fusão com outras filiadas mais fortes. Nas palavras de um dos dirigentes, a rentabilidade, para o sistema de crédito cooperativo, passou a representar:

[...] a pura sobrevivência, porque o sistema cooperativo não visa ao lucro. A sobra do final do ano vai, parte para a reserva, e parte para o capital social. O sócio de uma cooperativa quer que o seu capital cresça. Então, para a cooperativa sobreviver, tem que gerar essa sobra e tem que mostrar para o seu associado que, com a sobra, o capital social dele foi rentabilizado. Isso faz com que a cooperativa seja eficiente e cresça no mercado. A rentabilidade é muito mais pela necessidade de crescimento no mercado e de devolver ao associado a sobra que ele está trabalhando para que aconteça, do que para ter lucro. [...] Porque ninguém monta um negócio desse tamanho para perder dinheiro. $O$ associado vai exigir isso no final do exercício.

O segundo aspecto fundamental para a compreensão da nova identidade criada é a opção por se tornar um sistema totalmente aberto ao mercado, ou seja, integralmente composto de cooperativas de livre admissão. Essa decisão certamente representou um divisor de águas para a Central e suas filiadas, considerando as origens e o forte vínculo da maioria delas com o meio rural. Todavia, a Central Sicredi PR lutou pela possibilidade de converter suas filiadas ao regime de livre admissão, e esta mudança veio favorecer seus interesses de crescimento e diversificação de riscos. 0 interesse pela livre admissão já existia desde quando a Central paranaense foi constituída. Contudo até a criação do Sistema Sicredi Interestadual, os dirigentes da Central enxergavam na livre admissão apenas um meio de captar recursos de outros segmentos da economia para ajudar no 
financiamento da atividade rural. Além disso, havia inicialmente rejeição à ideia de acolher, em uma mesma cooperativa, público rural e urbano, pois temia-se que o controle da cooperativa acabaria sendo perdido para grupos de interesse urbano, prejudicando os que ne. 3.321/2005, o Sicredi havia iniciado um projeto de desenvolvimento do sistema em grandes centros urbanos. Entre os dirigentes da Central Sicredi PR, a resistência à abertura foi sendo derrubada, em parte, graças a visitas feitas a sistemas de crédito cooperativo na Europa, Canadá e Estados Unidos em que a livre admissão existia há muito tempo e os grupos fundadores continuavam no controle.

Quanto à participação do crédito rural no futuro do Sistema Sicredi, as opiniões de antigos e novos dirigentes também divergem. Os primeiros temem que os produtores rurais acabem perdendo o poder de decisão nas cooperativas e, consequentemente, deixem de ter suas necessidades atendidas. Os novos dirigentes sustentam que o crédito rural, não sendo mais o principal produto, continuará representando um fator importante nos negócios do sistema.

0 terceiro aspecto essencial para a caracterização da identidade do Sistema Sicredi é sua atual estrutura de governança. A primeira versão do modelo de governança do Sicredi surgiu em 2000, com a constituição da Confederação Sicredi e do Conselho Deliberativo do Sicredi. Este último era formado pelos presidentes das Centrais integrantes do sistema e deliberava sobre as propostas apresentadas pelo Bansicredi e pela Confederação com base na proporção de cooperativas representadas por cada membro.

Em abril de 2006, o Conselho Deliberativo do Sicredi deu início ao Projeto de Revisão e Padronização Organizacional (PRPO), que, dividido em três fases, abrangia todos os níveis do sistema, e objetivava modernizar a estrutura do Sicredi e estimular a maior profissionalização de seus quadros. As discussões no âmbito do Conselho Deliberativo a respeito da terceira fase do projeto prolongaram-se de dezembro de 2007 a julho de 2008, em função, principalmente, de divergências de opinião existentes entre os dirigentes do Banco e da Confederação acerca do modelo de governança e da estrutura patrimonial a serem adotados. Finalmente, em setembro de 2008, cooperativas singulares e centrais aprovaram a proposta definitiva para essa fase, cuja grande inovação foi a criação de uma holding para o sistema. A Sicredi Participações S/A possui uma Diretoria Executiva contratada, que reporta ao Conselho de Administração, composto por presidentes das centrais e de algumas singulares.

De acordo com os dirigentes, o objetivo fundamental da reestruturação foi permitir a profissionalização da gestão em todos os níveis do sistema, com vistas a poder competir no mercado financeiro, mas mantendo a estrutura de representação e de liderança por parte dos associados. Outra característica, destacada pelos dirigentes, é a unidade de comando. Antes, a responsabilidade pela gestão do sistema era difusa. Banco e Confederação tinham suas atividades pautadas em diferentes bases legais, pois o primeiro é uma sociedade anônima e a segunda, uma sociedade cooperativa. Um dos entrevistados explicou assim a decisão:

\begin{abstract}
Analisamos e optamos pela holding para profissionalizar a estrutura, e que oferecia o que a gente queria, que é ter todos os serviços financeiros à disposição do associado, de tal forma que ele seja fiel e não precise ter conta em outro banco, e de forma que você possa contratar executivos de mercado, trocar quando necessário, sem afetar a governança. Você tem uma representação muito clara das cooperativas no conselho da Sicredipar, $e$ tem um comando executivo. [...] você tem uma assembleia anual dos controladores (cooperativas singulares e centrais), para prestação de contas, e elege os membros do conselho. Esse conselho tem a atribuição de contratar os executivos. Você contrata, depois ele passa a ser eleito no banco, passa a ser membro estatutário. [...] Você pode convocar uma assembleia e trocar a escalação. [...] Você tem um profissionalismo mais direto.
\end{abstract}

A centralização do comando do sistema em uma holding acima das entidades de terceiro nível sugere, em princípio, o distanciamento entre os associados e o poder de decisão ainda maior do que antes. Todavia os novos dirigentes sustentam que o novo modelo de governança fortaleceu a representação das bases no processo decisório:

Nós fortalecemos as cooperativas com a reforma estatutária, [...], e as cooperativas têm hoje os seus representantes na holding, que antes não tinham. o Conselho Deliberativo era composto apenas pelas centrais. [...] E hoje as cooperativas e as centrais têm efetivamente o comando do Sicredi, porque no modelo anterior você tinha o Presidente do Banco, eleito pelos seus acionistas, e ele tinha um colegiado, mas não tinha um Conselho de Administração sobre 
ele, e a Confederação tinha também uma diretoria, eleita em outros moldes, e você gerava esse conflito, [...]. Então, com isso, nós entendemos que fortalecemos o sistema, porque você tem um controle efetivo e uma responsabilidade muito clara. Antes, o Conselho Deliberativo tinha a autoridade, mas não tinha a responsabilidade, porque ele não era formal. Hoje o Conselho de Administração é formal, é o conselho de uma $S / A$ e são representantes das cooperativas, então você tem que respeitar as regras do cooperativismo e também as regras das sociedades anônimas.

Nos dois últimos anos do período analisado, com o sucesso da reestruturação do sistema e a legitimação do modelo de conglomerado financeiro que fundamentou a constituição da Sicredipar, os dirigentes da Central Sicredi PR passaram a dar grande ênfase à oportunidade de estabelecer parcerias internacionais com vistas ao intercâmbio de experiências e tecnologias e, sobretudo, à captação de excedentes financeiros de sistemas cooperativos estrangeiros para aplicação no mercado brasileiro.

\section{Conclusões}

O pressuposto de que o robusto desenvolvimento da Central Sicredi PR estaria apoiado, entre outros fatores, na capacidade de atualização de sua visão de mundo, mostrou-se válido no presente caso. 0 levantamento dos esquemas interpretativos da Central revelou que as mudanças mais significativas ocorreram entre o início do período de análise (1995) e a consolidação do processo de integração do Sistema Sicredi Interestadual (1999-2000). Enquanto independente, a Central paranaense tinha o desenvolvimento da atividade rural local como objetivo principal. Com sua integração, a Central foi inserida em um novo projeto, focado no potencial de expansão do sistema com seu banco próprio, que imprimiu mudanças significativas em seus esquemas interpretativos, resultando na construção de uma nova identidade organizacional. Tais mudanças evidenciaram o fato de que as lógicas institucionais predominantes na Central paranaense e na Central gaúcha eram distintas. Enquanto a primeira mantinha uma perspectiva baseada em crenças e valores oriundos das cooperativas agrícolas do Estado, a segunda pautava suas ações em uma lógica própria do mercado financeiro.

Estratégias institucionais foram postas em prática com o intuito de proporcionar condições mais favoráveis à realização de objetivos da organização e, à medida que tais estratégias foram tendo êxito, produziram reflexos econômicos positivos e o projeto de desenvolvimento foi ganhando maior legitimidade dentro e fora da organização. Com isso, os elementos constitutivos da visão de mundo pós-integração do Sicredi se fortaleceram entre os dirigentes, ao mesmo tempo em que a organização conquistou mais credibilidade e, por conseguinte, mais espaço para novas estratégias institucionais. Verificamos, assim, que as estratégias institucionais não foram simplesmente resultantes das mudanças na visão de mundo predominante, mas mantiveram com estas uma relação de reciprocidade, por meio da qual o Sistema Sicredi construiu uma nova identidade, focada no desenvolvimento do próprio sistema. A liderança do Bansicredi foi decisiva nesse processo, funcionando como um agente transmissor de valores, interesses e práticas comuns nas instituições bancárias para dentro do sistema de crédito cooperativo.

A maior parte das estratégias institucionais identificadas foram estratégias deliberadas de pertencimento, por meio das quais o Sistema Sicredi procurou derrubar barreiras normativas para ampliar suas possibilidades de negócios. Apenas duas estratégias de padronização foram caracterizadas: (i) a primeira pela participação do Sicredi nos estudos que subsidiaram a elaboração de normas que definiram as atribuições específicas das cooperativas centrais, estratégia que visou à obtenção de respaldo legal para práticas que já estavam legitimadas internamente, mas que poderiam ser questionadas; e (ii) a segunda por um pedido, feito ao Banco Central, de autorização para consolidar a contabilidade de todas as entidades do sistema.

Lawrence (1999) afirma que as estratégias de pertencimento têm boa chance de serem bem sucedidas nos ambientes em que o nível de estruturação é baixo, e essa era uma característica do ambiente institucional do cooperativismo de crédito no Brasil, tendo em vista que sua organização em sistemas e a regulamentação de suas atividades encontravam-se ainda em fase de desenvolvimento. Além disso, os dirigentes entrevistados argumentaram que o Sicredi passou a ser visto pelo órgão regulador como uma referência no setor para o estabelecimento de normas, condição que corrobora a proposição de Lawrence (1999) de que:

\footnotetext{
A habilidade de uma organização de afetar as regras de pertencimento de um campo organizacional está positivamente associada com seu controle sobre a informação institucional e com o grau em que tal organização é percebida como uma líder no campo.
} 


\section{Referências}

ASSOCIAÇ̃̃O NACIONAL DAS COOPERATIVAS DE CRÉDITO - ANCC. Lula aprova regras para o Sistema Nacional de Crédito Cooperativo. Disponível em: <http://www.ancc. com.br/modules/news/article.php?storyid=7>. Acesso em: 11 fev. 2010.

BARDIN, L. Análise de conteúdo. Lisboa: Edições 70, 2004.

BARR, P. S.; STIMPERT, J. L.; HUFF, A. Cognitive change, strategic action, and organizational renewal. Strategic Management Journal, v. 13, n. 1, p. 15-36, 1992.

BARTUNEK, J. Changing interpretive schemes and organizational restructuring: the example of a religious order. Administrative Science Quarterly, v. 29, n. 3, p. 355-372, 1984.

BATTILANA, J. Agency and institutions: the enabling role of individuals social position. Organization, v. 13, n. 5, p. 653-676, 2006.

BERGER, P.; LUCKMANN, T. A construção social da realidade. 5. ed. Petrópolis: Vozes, 1983.

CLEMENS, E.; COOK, J. Politics and institutionalism: explaining durability and change. Annual Review of Sociology, v. 25, n. 1, p. 441-466, 1999.

DIMAGGIO, P.; POWELL, W. The iron cage revisited: institutional isomorphism and collective rationality in organizational fields. American Sociological Review, v. 48, n. 2, 1983.

EMIRBAYER, M.; MISCHE, A. What is agency? American Journal of Sociology, v. 103, n. 4, p. 962-1023, 1998.

FRIEDLAND, R.; ALFORD, R. Bringing society back in: symbols, practices, and institutional contradictions. In: POWELL, W.; DIMAGGIO, P. (Ed.). The new institutionalism in organizational analysis. Chicago: University of Chicago Press, 1991.

GIDDENS, A. A constituição da sociedade. São Paulo: Martins Fontes, 1989.

LAWRENCE, T. Institutional strategy. Journal of Management, v. 25, n. 2, p. 161-188, 1999.

MACHADO-DA-SILVA, C.; FONSECA, V.; CRUBELLATE, J. Estrutura, agência e interpretação: elementos para uma abordagem recursiva do processo de institucionalização. Revista de Administração Contemporânea, edição especial, p. 9-39, 2005.
MACHADO-DA-SILVA, C.; FONSECA, V.; FERNANDES, B. Mudança e estratégia nas organizações: perspectivas cognitiva e institucional. In: VIEIRA, M.; OLIVEIRA, L. (Org.). Administração contemporânea - perspectivas estratégicas. São Paulo: Atlas, 1999.

MACHADO-DA-SILVA, C.; NOGUEIRA, E. Identidade organizacional: um caso de manutenção, outro de mudança. Revista de Administração Contemporânea, v. 5, edição especial, p. 35-58, 2001.

PORTAL DO COOPERATIVISMO DE CRÉDITO. Conheça o Sicredi. Disponível em: <http://www.cooperativismodecredito.com.br/noticias/labels/SICREDI.html>. Acesso em: 11 fev. 2010.

PORTAL DO COOPERATIVISMO DE CRÉDITO. Sancionada nova lei para as cooperativas de crédito. Disponível em: <http:// www.cooperativismodecredito.com.br/noticias/2009/04/sancionada-nova-lei-para-as.html>. Acesso em: 11 fev. 2010.

RANSON, S.; HINNINGS, B.; GREENWOOD, R. The structuring of organizational structures. Administrative Science Quarterly, v. 25, n. 1, p. 1-17, 1980.

SCOTT, W. The adolescence of institutional theory. Administrative Science Quarterly, v. 32, n. 4, p. 493-511, 1987.

SCOTT, W. Organizations. 3. ed. New Jersey: Prentice-Hall, 1992.

THORNTON, P. The rise of the corporation in a craft industry: conflict and conformity in institutional logics. Academy of Management Journal, v. 45, n. 1, p. 81-101, 2002.

THORNTON, P.; OCASIO, W. Institutional logics and the historical contingency of power in organizations: executive succession in the higher education publishing industry. American Journal of Sociology, v. 105, n. 3, p. 801-843, 1999.

THORNTON, P.; OCASIO, W. Institutional logics. In: GREENWOOD, R. et al. (Ed.). The sage handbook of organizational institutionalism. London: Sage, 2008.

Recebido: 26/09/2011

Received: 09/26/2011

Aprovado: $20 / 07 / 2012$

Approved: 07/20/2012 